\title{
Educação, Direitos Humanos e formação de professores: reflexões e proposições
}

\author{
Education, Human Rights and teacher training: reflections \\ and propositions
}

\section{Educación, Derechos Humanos y formación de professores: reflexiones y proposiciones}

\author{
Kilza Fernanda Moreira de Viveiros ${ }^{1}$ \\ ORCID: https://orcid.org/0000-0003-1243-7595
}

\begin{abstract}
Resumo: Artigo trata na construção de reflexões e proposições sobre a relação da educação, direitos humanos e formação de professores para atuarem na educação básica. Aborda a relação entre o poder político e a sociedade a partir da análise do Estado como instância promotora de direitos e pelos mecanismos que o mesmo se apodera para forjá-los na educação. Analisa o papel das reformas curriculares em conformidade às políticas dominantes. Discute a formação de professores e sua relação com a pobreza, com as desigualdades sociais e direitos humanos. Os fundamentos que norteiam as análises são do campo de conhecimento educacional e pedagógico. Para elucidações contextuais apropria-se de referencial sócio histórico, das políticas educacionais e políticas curriculares. Permite o diálogo com o objeto da formação e atuação de professores na área dos direitos humanos. Artigo se organiza metodologicamente em cinco tópicos a saber: Introdução, $\mathrm{O}$ Estado e a promoção de direitos, Currículo enquanto princípio político, Formação de professores para os direitos humanos e Considerações. Conclui ponderando a importância do papel do Estado na promoção dos direitos humanos a partir de políticas públicas comprometidas com a educação e com a formação de professores para o trabalho com os vulneráveis, as desigualdades sociais e os direitos humanos. Também chama a atenção da educação para os direitos humanos nos diferentes níveis e modalidades de ensino, expansiva à comunidade escolar.
\end{abstract}

Palavras-chave: Educação. Direitos humanos. Formação de Professores. Estado. Currículo.

Abstract: Article deals in the construction of reflections and propositions on the relationship of education, human rights and teacher training to work in basic education. It addresses the relationship between political power and society based on the analysis of the State as a promoter of rights and the mechanisms it takes to forge them in education. It analyses the role of curricular reforms in line with dominant policies. It discusses teacher education and its relation to poverty, social inequalities and human rights. The foundations that guide the analyses are the field of educational and pedagogical knowledge. For contextual elucidations it appropriates the socio-historical reference, educational policies and curricular policies. It allows dialogue with the subject of the training and action of teachers in the area of human rights. Article is organized methodologically in five topics: Introduction, The State and the promotion of rights, Curriculum as a political principle, Training of teachers for human rights and Considerations. He concludes by considering the importance of the role of the State in the promotion of human rights from public policies committed to education and teacher training for working with the vulnerable, social inequalities and human rights. It also draws the attention of education for human rights in the different levels and modalities of education, expansive to the school community.

\footnotetext{
${ }^{1}$ Professora Doutora do Departamento de Fundamentos e Políticas da Educação da UFRN, da área de história da educação, políticas educacionais, pobreza e desigualdade social. E-mail: kilza.fernanda@hotmail.com.
} 
Keywords: Education. Human rights. Teacher Training. State. Curriculum.

Resumen: Artículo trata en la construcción de reflexiones y proposiciones sobre la relación de la educación, derechos humanos y formación del professora do para actuar en la educación básica. Aborda la relación entre el poder político y la sociedad a partir del análisis del Estado como instancia promotora de derechos y por los mecanismos que el mismo se apodera para forjarlos en la educación. Analiza el papel de las reformas curriculares en consonancia con las políticas dominantes. Discute la formación de profesores y su relación con la pobreza, con las desigualdades sociales y derechos humanos. Los fundamentos que guían los análisis son del campo de conocimiento educativo y pedagógico. Para aclaraciones contextuales se apropia de un marco socio histórico, políticas educativas y políticas curriculares. Permite el diálogo con el objeto de formar y actuar a los docentes en el área de derechos humanos. El artículo se organiza metodológicamente en cinco temas, a saber: Introducción, El Estado y la promoción de los derechos, El currículo como principio político, La formación del profesorado en derechos humanos y Consideraciones. Se concluye considerando la importancia del papel del Estado en la promoción de los derechos humanos a partir de políticas públicas comprometidas con la educación y la formación de docentes para trabajar con las personas vulnerables, las desigualdades sociales y los derechos humanos. También llama la atención de la educación en materia de derechos humanos en los diferentes niveles y modalidades de educación, expandiéndose a la comunidad escolar.

Palabras clave: Educación. Derechos humanos. Formación del profesorado. Estado. Plan de estudios.

\section{INTRODUÇÃO}

Este artigo se circunscreve numa oportunidade de construirmos reflexões sobre a relação da educação com os direitos Humanos e a formação de professores na perspectiva das relações de poder que se constroem a partir dessas três categorias. Na perspectiva das relações entre o poder político e os cidadãos, e do papel que nos cabe enquanto formadora de educadores, assumida numa cultura combativa aos direitos humanos.

O ensejo da temática escolhida para este artigo é fundamental no contexto histórico e político que atravessamos, por ser este meio, uma instância de reflexões, debates, além de ser formadora de opiniões no campo educacional muito distante da imparcialidade. A centralidade deste é essencial para o debate sobre a formação de professores no conjunto de mudanças em âmbito social e educacional brasileiro, que tem se concretizado fundamentadas em ideologias neoliberais.

Destacamos que a nossa escrita se dá por sermos formadora a partir do campo pedagógico, da história da educação e por estudarmos o objeto 'pobreza' e sua relação com a educação, nos içamos no campo dos direitos humanos com ênfase ao direito à educação. Portanto as nossas proposições se originam desses direitos e, na tentativa de sermos fiel às demais categorias já assinaladas anteriormente, iremos abordá-las com o desafio de tecermos algumas reflexões. 
Para um início de diálogo, trataremos a nossa fala em três dimensões. A primeira onde trazemos o Estado à responsabilidade de provedor de direitos e a necessária participação social na vigilância da concretização desses direitos. A segunda dimensão chamamos a atenção dos mecanismos que o Estado se apropria para forjar esses direitos, sobretudo no âmbito educacional como as reformas curriculares, Base Nacional Comum Curricular, e como consequência, a terceira dimensão, provocada por esse contexto, que é a formação dos professores sua relação com a pobreza, com as desigualdades sociais e direitos humanos.

\section{O ESTADO E A PROMOÇÃO DE DIREITOS}

As clássicas relações de poder assentam numa linha de segregação entre o Estado e a sociedade. As democracias, como modelo político, formam a sua legitimidade na escolha livre e periódica dos cidadãos e na responsabilização única dos seus representantes como pessoas de comprometimento social, econômico e de igualdade de direitos. Este modelo pelo qual os cidadãos esgotam o seu papel de intervenção quando do momento do sufrágio, está visivelmente ultrapassado. Os agentes políticos mostram-se incapazes de realizarem, sozinhos, as tarefas de empenho com a cidadania e a solidariedade que é exigida em nome dos direitos.

Os direitos humanos pedem aos Estados um novo protagonismo e uma nova função articuladora com a participação efetiva dos cidadãos na garantia do seu cumprimento. O direito a ter direito (HANNAH ARENDT, 2012) traduz a essência dos direitos humanos e obriga o comprometimento dos Estados com a condição de cidadania plena.

O modelo social comprometido com a dignidade humana obriga à transformação do modelo político. A lógica do apartamento entre o Estado e a sociedade civil deve ceder lugar à uma lógica de articulação e de comprometimento recíproco. Todos os dias a realidade nos evidencia a insuficiência do Estado na realização dos direitos humanos e na formação de uma comunidade mais digna e mais humana. Nas sociedades neoliberais isso se cristaliza na negação de direitos básicos assegurados pelo exercício das meritocracias, na banalização da corrupção e das ideologias dominantes. 
Ressaltamos que não podemos esquecer a responsabilidade do Estado em assegurar às pessoas os seus direitos de cidadania e de direitos humanos. Os direitos humanos mobilizam para uma ação que está simultaneamente dentro e fora da lei e atravessam as fronteiras do Estado. Esses direitos podem ser um valor associado à cultura e tradição de povos, por exemplo.

Aceitar os direitos humanos como responsabilidade, significa tornar necessária a nova função do Estado, que é de articular as tarefas políticas da sociedade através da garantia desses direitos, da garantia da comunicação entre representantes e representados, da relação entre partidos políticos e cidadania. $\mathrm{Da}$ garantia social, de poder viver a pólis de fato e de direito.

Nesse contexto refletimos sobre o que é considerado essencial numa ação política para o cumprimento dos direitos humanos e respeito aos cidadãos. $O$ essencial é o investimento do Estado em educação, em políticas públicas que asseguram a garantia de ter direitos e serem válidos. Tem que haver investimento numa educação igualitária e de qualidade, comprometida socialmente e politicamente. Respeitada enquanto um direito humano, social, portanto vital para 0 exercício da cidadania. Esse direito é o que vai assegurar o desenvolvimento social e humano.

Tal respeito se materializa quando o Estado se compromete com políticas públicas para a educação como princípio básico de desenvolvimento social. Com a criação de políticas de Estado para a Educação e não de governo. Estas muitas vezes de cunho interesseiro, meritocrático e descontinuado. Sem nenhuma configuração responsável à longo prazo, tendo e $\mathrm{m}$ vista que os resultados de investimento no campo educacional não se solidifica em quatro anos e sim no desenvolvimento histórico de um povo.

As políticas de Estado, quando alinhadas ao cumprimento de direitos humanos, e aqui falamos por excelência no direito à educação, reflete ações de empenho com as instâncias de formação de professores para atuarem na educação básica de modo ininterrupto, , no aumento da oferta de vagas em estabelecimentos oficiais de ensino, no comprometimento com a educação infantil enquanto etapa essencial da educação básica, com programas que visam a manutenção do ensino de qualidade e a permanência do aluno na escola. 
Quando nos reportamos à essas políticas nos dirigimos às minorias, aos pobres, aos desfavorecidos da sociedade liberal, daqueles que desconhecem seus direitos de cidadania negados pelo domínio e concentração de renda, além de mantenedor das desigualdades sociais.

Portanto o que nós refletimos não pode ser desligado de um discurso geral sobre inclusão, que considera também a situação de seres humanos mais frágeis e vulneráveis, como é o caso das pessoas da terceira idade, os deficientes, os LGBT's, os pobres, os esquecidos da cidade, como moradores de rua e encarcerados. Essa reflexão aponta, também, para a observação de que os velhos métodos de ação política para as instituições de recolhimento não funcionam, os velhos métodos de ação política para inserção social não funcionam, os velhos métodos de ação política para os sistemas prisionais, casa de reeducação de jovens infratores, não funcionam. Em todos esses planos percebemos a imposição de uma cultura conservadora e combativa aos direitos, ao contrário de se estabelecer uma cultura que assegure os direitos humanos.

Enquanto não fizermos emergir uma solução educativa, enquanto não pensarmos de maneira estratégica (CERTEAU,1990) a Educação, a sociedade e a política não adquirirá níveis mínimos de dignidade e de excelência e, continuaremos a escrever uma história difusa, uma história das elites, dos favorecidos e dos que ascendem ao poder.

Pensar estrategicamente a Educação é dar a ela a importância de uma ação transformadora humana e, sobretudo, social e política. Pensar a educação nessa perspectiva é tê-la como a própria ação política, portanto socialmente responsável. É reconhecê-la como um direito humano, para além da lei, é reconhecê-la como de fato e de direito. Nessa direção teremos a visibilidade sócio-política e histórica de um povo que se encaminha para o desenvolvimento humano e social.

A partir dessa orientação, é necessário refletirmos sobre os direitos individuais, que requerem uma consideração isenta de uma lógica numérica aferido por métodos que mensuram dados sociais. Cada ser humano é um ser único, ao mesmo tempo que é um universo, uma imensidão. É esta irredutibilidade que tem de estar presente no discurso dos direitos e na ação política. Quando falamos desse ser humano único, refletimos sobre as cifras estatísticas, por exemplo, dos números educacionais e os valores atribuídos pelos sistemas de avaliações que dispomos em 
nosso país, como Índice de Desenvolvimento da educação Básica - IDEB, por exemplo. Todos esses sistemas estão carregados de intencionalidades, todos estão à serviço de uma conformidade dos grupos de poder político, dos grupos hegemônicos e de poder econômico, se esquecendo do ser humano, seu processo de humanização mediante o gozo dos seus direitos.

É necessário conjecturarmos que os direitos humanos escapam, também, a lógica das fronteiras. Para tanto observamos que no século passado vimos indivíduos tornarem-se sujeitos de direitos em contextos internacionais nos processos imigratórios. À exemplo da União Europeia, a dignidade e os direitos do homem tornaram-se critérios de ação política nos últimos anos. No entanto, tal fato requer cuidados, uma vez que, na unificação de interesses políticos e econômicos, sempre há um lado mais fraco, ou seja, mais pobre, mais vulnerável. A ideia de uma economia forte, tende a fortalecer muito mais os mais ricos, do que os mais pobres. Tende a assegurar muito mais direitos a quem os tem, do que aos que não tem. É nesse bojo, que se mantém as ideologias dominantes e a adesão das políticas de mérito, mesmo tendo as organizações internacionais, como a Organização das Nações Unidas - ONU, corresponsáveis pela proteção dos direitos humanos.

Ainda, ao pensarmos sobre as fronteiras, outro aspecto relevante são as políticas de imigração e o cumprimento dos direitos destes. Aqui nos cabe uma reflexão embrionária, uma vez que nosso país não tinha, até então, expressado publicamente a preocupação com as nossas fronteiras geográficas, estando estas resolvidas (grifo nosso) para a grande maioria dos cidadãos brasileiros. Talvez esse fato se dá pela importância geopolítica do Brasil na América do Sul, e, quem sabe, pela ação estratégica de nossas forças de segurança nacional. No entanto, essa configuração tendeu a se modificar dado aos contextos de crise econômica e política de países vizinhos, como o caso da Venezuela. Desta maneira a nossa reflexão paira sobre a urgente necessidade de criação de políticas públicas para a imigração comprometida em assegurar os direitos humanos àqueles que deixam a suas terras e tentam prosperar noutra, e nesse caminho a garantia ao direito à educação aos imigrantes.

Nessa perspectiva o Estado deve prosseguir a partir de uma política de justiça social afim de garantir a consecução da dignidade humana. Para isso, é fundamental que se fortaleçam os valores democráticos, destacando a liberdade política, a 
liberdade de expressão e comunicação em âmbito social e nesse contexto se insere também a Educação.

Nesse caminho, acreditamos que a educação é tema essencial ao debate público a ser fomentada pelo Estado, apesar de não ter conhecimento de tê-la sido na agenda política dos candidatos eleitos aos governos de países como o Brasil, México e Colômbia. Ao nosso entendimento para esses países a educação não parece ser uma prioridade nas campanhas eleitorais e, portanto em seus programas de governo, deixando a sociedade vulnerável à esse direito, a educação, e aos direitos humanos, de maneira ampla.

No caso do Brasil os ataques aos direitos humanos, às liberdades democráticas tão duramente conquistadas ao longo da história e, às políticas sociais destinadas à melhoria das condições de vida e de trabalho, foram ferindo a dignidade dos brasileiros, despertando repulsas no âmbito da sociedade. O espanto inicial virou inconformismo e logo veemente repúdio às suas posições antidemocráticas que punham em risco diretamente a educação, mulheres, crianças, ativistas dos movimentos sociais organizados defensores dos direitos humanos, ambientalistas e povos indígenas. Retrocedendo aos tempos da ditadura, estamos ameaçados por adversários políticos, com a repressão já experimentada pelo regime militar. Esses defensores desclassificam os movimentos sociais, a luta em defesa dos direitos humanos e os consideram como ativismo, que ameaça a família e a sociedade. A partir de um discurso fundamentalista e práticas fascistas a intenção é fazer retroagir a roda da história, revertendo conquistas sociais e trabalhistas, e por que não dizer dos direitos humanos.

Vale frisarmos que os direitos humanos convivem com uma realidade assustadora, pois a grande maioria da população mundial não é sujeito de direitos humanos, e sim, segundo Boaventura de Souza Santos (2013), objeto de discursos de direitos humanos. Dessa maneira devemos nos perguntar se os direitos humanos servem eficazmente na luta dos excluídos, dos explorados e dos discriminados, ou se, pelo contrário, a tornam mais difícil.

Nesse bojo questionamos: E a educação? Quais as intencionalidades desse momento que vivemos? Quais as artimanhas preparadas por uma ideologia que se contrapõe às conquistas históricas e resultante de tantas lutas? 
Poderíamos tentar responder tais questões, mas a nossa finalidade é tecer proposições e deixar ao critério de cada um, a sua síntese. No entanto nós poderíamos adentrar o universo histórico do Brasil e trazer toda a construção dessas conquistas, mas infelizmente não trazemos tal objetivo como ponto de aprofundamento.

\section{CURRÍCULO ENQUANTO PRINCÍPIO POLÍTICO}

A temática desse artigo nos conduz a um caminho capaz de subsidiar as nossas reflexões compreendendo que a grande perda que se consolida atualmente é a usurpação dos direitos humanos e educacionais. Perda que se circunscreve quando os antidemocratas nos impõem, sem o debate necessário e aprofundado, uma reforma curricular que contrapõe aos diversos segmentos da educação, conquistados com a Constituição e Lei de Diretrizes e Bases da educação Nacional vigentes, e entre eles destacamos o direito à educação, o campo da formação e da pesquisa educacional.

Quando se fala em currículo, se fala de uma política ampla, e de grande responsabilidade na construção do pensamento sócio educacional de um país. O currículo é um campo do conhecimento pedagógico de ampla relevância na construção da nossa Escola e, portanto, da nossa sociedade. Ele é carregado de concepções históricas, filosóficas, sociológicas, psicológicas, econômicas e políticas determinantes ao processo construtor de um tipo de educação, de sociedade, de homem e de país.

Nele se imputam as ideologias, as formas e modos de poder, incluindo os seus limites. Também atribuímos a ele cumprimento legal, emancipação, mudança, e sobretudo, liberdade e cidadania. Portanto o currículo se evidencia como princípio político que, de uma maneira, ou de outra, representa as intencionalidades de quem as organiza.

Ao acompanharmos a construção política da Base Nacional Comum Curricular -BNCC, no Brasil, para além das questões efetivamente curriculares, constatamos facilmente que sua maior crítica advém das questões concernentes a ausência de uma governança escolar democrática. Expressão esta cunhada pela coletânea "La gobernanta escolar democrática", organizada pelos espanhóis Jordi 
Collet e Antoni Tort (2016). Essa governança tem nos trazido importantes contribuições para pensar o processo de construção e implementação da BNCC.

Um dos pontos de partida para esses autores é compreender de que "as respostas no mundo da educação e da escolaridade estavam começando a se construir somente a partir do 'como', por exemplo: como avaliar, como melhorar resultados, como liderar bem uma escola. Ou seja, interessava uma volta a indagações básicas sobre para que educar, que escola desejamos construir. Para Collet e Tort o que importa é que, em torno dessas questões, os modelos neoliberal e neoconservador têm apresentado predomínio político nos direcionamentos das políticas de públicas para a escolarização.

Acerca da lógica neoliberal, um dos capítulos escrito nos oferece uma indispensável descrição da despolitização da educação, ora predominante. À medida em que os princípios da escolha e da competitividade adquirem centralidade, as políticas têm sido construídas a partir da eliminação do político e da ênfase nas práticas empresariais. Destaca o sociólogo britânico Stephen Ball (2011), que "a despolitização opera para converter as condições coletivas de experiência em problemas pessoais, substituindo as decisões políticas e econômicas por fracassos e responsabilidades individuais".

No que tange à agenda neoconservadora, merece destaque a análise oferecida pelo historiador Antonio Viñao Frago. Argumentando acerca do contexto espanhol, Viñao (2006) aponta para uma intensificação das lógicas burocráticas e suas formas de controle. Isto seria materializado, por exemplo, nas seguintes práticas:

[...] regulação detalhista de um currículo baseado sobretudo na aprendizagem de alguns conteúdos determinados, controle, ordem, estandardização, prestação de contas e controle de resultados, predomínio de ideias e formas de pensar tradicionais, hierarquização, burocratização, reforço das estruturas e modos autoritários de governo e gestão, assim como a índole seletiva dos sistemas educativos, etc. (FRAGA. 2006. p. 42).

Outros capítulos compõem a coletânea; mas, para este artigo ainda desejo chamar a atenção para a alternativa política proposta ao final da obra, qual seja: a governança escolar democrática. Ultrapassando as perspectivas neoliberal e neoconservadora, os autores propõem novos modos de governança colocados a serviço de processos de justiça e democracia. Em sua argumentação, construir lógicas, conceitos, formas de governo e identidades alternativas à governança da 
nova gestão pública requer, conforme temos dito, fortes doses de perguntas radicais (SUBIRATS. 2004). Formular perguntas radicais pode encaminhar a construção de uma educação democrática que, na acepção de Joan Subirats (2004) em seu capítulo na coletânea, favorece a constituição de uma inovação social caracterizada pela democracia do comum. Assim sendo, encontramos nesta obra um representativo de boas análises e proposições para a educação contemporânea que nos ajudaram na construção desse texto.

Em termos de políticas curriculares, a partir da BNCC, precisamos seguir apostando em leituras que oportunizem a mobilização de questões radicais e, ao mesmo tempo, ofereçam ferramentas para que os coletivos escolares possam promover outras formas de governança mais solidárias, mais democráticas e que visem a construção do homem humanizado, social e ser de direitos humanos.

Também frisamos a necessidade de criação de acentos de debates incansáveis. Resistentes às formas de imposição do pensamento neoconservador e antidemocrático na educação e, penso que um desses lugares está na formação de profissionais da educação. Em sua relação com o as fundamentações específicas do conhecimento curricular, das políticas públicas para a educação e dos espaços de aplicação desses conhecimentos. É necessário que se estabeleça e se mantenha, minimamente, o diálogo com entre as instâncias de formação e as instâncias políticas de aplicação como as escolas, as instituições de formação, as universidades. É necessário criarmos possibilidades de tencionamento entre as ideologias impostas pelo aspecto econômico e os direitos sociais, humanos e educacionais.

Lembramos, nessa oportunidade, que a educação deve primar pela formação humana, cultural e política do indivíduo, a fim de que se fortaleça a noção de cidadania enquanto pertencimento a uma coletividade, caso contrário o poder público continuará se empoderando gradativamente perante a sociedade, no que se refere a tomada de decisões e investimento em políticas públicas. Segundo Freire (1987, p. 28) A partir do sistema educativo adotado por um país, pode-se contribuir para a reprodução de uma ideologia dominante ou trabalhar a favor da emancipação de uma sociedade, quando se reforça a capacidade crítica do educando, sua curiosidade, sua insubmissão. 
Diante das palavras do grande mestre Paulo Freire, chegamos à nossa terceira e última categoria proposta para as nossas reflexões. A formação de professores nesse contexto atual.

\section{FORMAÇÃO DE PROFESSORES PARA OS DIREITOS HUMANOS}

Sem ficarmos distantes das análises até aqui descritas sobre a Base Nacional Comum Curricular, o campo da formação de professores também se desenha em chão escorregadio em meio às mudanças que ameaçam os valores sociais democráticos e de direitos. Isto por que falar de formação é falar de mim e de vocês. Talvez seja tão fácil e, ao mesmo tempo, tão difícil. Fácil por vivenciarmos a práxis diariamente e tão difícil por idealizarmos objetivos libertadores tão advertidos!

Pensar a educação na perspectiva da formação de professores num tempo demarcado por crises políticas do Estado, das instituições, dos governos, dos processos pedagógicos e principalmente pela crise dos sujeitos, se efetiva num grande e inesgotável desafio. Pensarmos essa crise e pensarmos o contemporâneo, esse tempo em que refletimos enquanto ele acontece e a coloca na centralidade de nas nossas vivências. Interrompemos crenças, dogmas, e modos de pensar e agir para nos abrirmos para o novo. Esse novo, por sua vez, nos obriga a vivê-lo, experimentá-lo e pensá-lo a partir da própria posição em que estamos: aqui e agora. Percebemos, então, que nos constituímos mutuamente com a nossa sociedade, uma sociedade onde novos velhos valores retornam rebuscados de poderio e permeado de intenções tão menos humanas, que até o pensamento teórico contemporâneo não consegue explicar.

No momento presente é inevitável tentar se abster desse novo entre a sensação de impossibilidade diante dos valores constituídos e a falta de certeza em relação ao futuro. Vamos escrevendo uma história demarcada pelo provisório, pela precipitação e inseguranças. Pelo que devemos fazer no exato momento para garantir o agora e, pela cultura do medo.

Nesse cenário brasileiro de incertezas em que nos encontramos, não podemos deixar de fazer alguns apontamentos sobre a tocante questão da formação de professores, que, a nosso ver, merece uma atenção especial, já que muito dos 
efeitos positivos e negativos que vivenciamos na educação se baseiam no tipo e na qualidade da formação que nossos educadores estão recebendo.

Desde a criação da Lei de Diretrizes e Bases da Educação Nacional LDB, Lei 9.394/96, e antes mesmo de sua aprovação, existiam inúmeros debates sobre a formação mínima exigida aos professores para a atuação na educação básica. A defesa, sobretudo da Associação Nacional pela Formação dos Profissionais da Educação-ANFOPE, Associação Nacional de Pós-graduação e Pesquisa em Educação - ANPED, era por uma formação técnica e didática em nível superior rompendo com a velha formação do currículo $3+1$, como salientado no artigo 62.

O artigo 82, da LDB salienta sobre a década da educação estremando a década 1997-2007. Em seu inciso IV, determina que até o fim da Década da Educação somente serão admitidos professores habilitados em nível superior ou formados por treinamento em serviço. (BRASIL, 1996). No entanto, esse inciso foi revogado pela Lei $\mathrm{n}^{\circ}$ 12.796, de 2013, apresentando outro problema, como comenta Saviani (2009, p. 148):

[...] a nova LDB promulgada, após diversas vicissitudes, em 20 de dezembro de 1996, não correspondeu a essa expectativa. Introduzindo como alternativa aos cursos de pedagogia e licenciatura os institutos superiores de educação e as Escolas Normais Superiores, a LDB sinalizou para uma política educacional tendente a efetuar um nivelamento por baixo: os institutos superiores de educação emergem como instituições de nível superior de segunda categoria, provendo uma formação mais aligeirada, mais barata, por meio de cursos de curta duração. (SAVIANI, 2009, p. 148).

O que é preocupante nisso tudo é que o novo Plano Nacional de Educação PNE. 2014-2024 faz uma menção semelhante a essa da LDB, na sua meta 15 visando.

[...] garantir, em regime de colaboração entre a União, os Estados, o Distrito Federal e os Municípios, no prazo de 1 (um) ano de vigência deste PNE, política nacional de formação dos profissionais da educação de que tratam os incisos I, II e III do caput do art. 61 da Lei no 9.394, de 20 de dezembro de 1996, assegurado que todos os professores e as professoras da educação básica possuam formação específica de nível superior, obtida em curso de licenciatura na área de conhecimento em que atuam.

Isto quer dizer que desde a promulgação da LBD, em 1996, até o fim da década da Educação no ano de 2007, o país não conseguiu formar todos os professores da educação básica em nível superior, principalmente na área de conhecimento em que atuam. 
Em síntese, passaram-se 18 anos até a criação do novo PNE, depois disto mais seis anos, e ainda nos deparamos com essa questão. Com isso resta nos inquerir: Quais as políticas públicas têm sido criadas para a superação desse déficit? Essas políticas ambicionam qualidade na formação dos professores? Como podemos falar em qualidade da educação brasileira se em pleno século XXI tendo professores sem formação em nível superior na área de conhecimento que em que atuam? A velha questão posta por Marx (2007), quem educa os futuros educadores nunca se fez tão presente.

Otaviano Helene em sua obra, publicada em 2013, Um Diagnóstico da Educação Brasileira e de Seu Financiamento, apresentava dados de 2011 que apontavam que $67 \%$ de estudantes estavam no ensino superior privado.

O panorama analisado por Nicholas Davies (2016) - 1996-2014 - apresenta uma forte preocupação com a qualidade da educação brasileira, principalmente no que diz respeito ao financiamento da educação e a formação dos professores que corroboram e atualizam o dado. De acordo com o IBGE, em 2016 a rede privada possuía $73 \%$ do total de estudantes do ensino superior. O que estamos querendo evidenciar entre as duas pesquisas é o crescimento da ocupação da formação está assentada em estabelecimentos privados. No entanto é importante dizer que não estamos julgando a qualidade dessas instituições nesse trabalho de formação, mas que precisamos pensar e também discutir o tipo de formação que os professores estão recebendo, bem como questionar onde estão as políticas de formação nas instituições públicas?

Já estamos com seis anos de vigência do PNE (2014-2024) e ao lermos apenas o relatório do $1^{\circ}$ ciclo de monitoramento das metas do PNE: biênio 20142016, podemos ficar mais preocupados. Nesse trabalho foi evidenciado que os docentes, com formação superior obtida em curso de licenciatura, na área de conhecimento em que atuam, é de $52,5 \%$, dados do ano de 2015. Ou seja, temos aproximadamente $47,5 \%$ de professores que ainda não tem formação superior especifica na área em que lecionam. Uma maior atenção deve ser dada as regiões Nordeste que apresentava apenas 38,2 \% e Norte com 46,5\% de docentes com formação superior exigida na meta 15. (Brasil. Instituto Nacional de Estudos e Pesquisas Educacionais Anísio Teixeira. Relatório do $1^{\circ}$ ciclo de monitoramento das metas do PNE: biênio 2014- 2016. - Brasília, DF: Inep, 2016.) 
Ficaremos mais quantos anos sem que todos professores da educação básica tenham formação superior? Sem que os professores tenham uma formação voltada para o contexto e que tenham a sua formação voltada aos direitos humanos?

É urgente colocarmos essa discussão em pauta para que possamos exigir dos entes federados a concretização da meta 15 deste PNE antes de 2024. E não só a meta 15 , precisamos lutar pela garantia da valorização real dos profissionais da educação. Não podemos perder os Planos de Vista! Não podemos sucumbir ao contexto ameaçador que coloca em dúvida os caminhos historiados até aqui e, tão pouco as nossas conquistas.

Devemos ficar atentos para as políticas que estão sendo desenvolvidas para o cumprimento dessas metas e, caso ainda não esteja sendo feito nada em alguns municípios, resta a nós da população, e que estamos preocupados com a educação, cobrarmos para que algo seja feito com urgência, antes de 2024.

Outra proposição que trazemos referente à formação dos professores paira sobre o desafio de educar em direitos humanos e, para isso é fundamental situarmos essa discussão a partir do conceito de formação de professores que a compreende como sendo a:

[...] área de conhecimentos, investigação e de propostas teóricas que, no
âmbito da Didática e da organização escolar, estuda os processos através
dos quais os professores - em formação ou em exercício - se implicam
individualmente ou em equipa, em experiências de aprendizagens através
dos quais adquirem ou melhoram os seus conhecimentos, competências e
disposições, e que lhes permite intervir profissionalmente no
desenvolvimento do seu ensino, do currículo e da escola, com o objetivo de
melhorar a qualidade da educação que os alunos recebem. (GARCIA. 1999,
p.26).

Mediante essa compreensão do que é formar professores cogitamos sobre relevância dessa temática para a sociedade que frequentemente muda e cada vez mais exige do sujeito autonomia e flexibilidade para transitar em diferentes grupos e se os (GATTI. 2010). professores são:

[...] que formam com o seu trabalho nas escolas, as sucessivas gerações que darão continuidade a um processo de civilização que vem se construindo em muitos séculos, processo que permite a busca, a criação e a manutenção de maiores e melhores condições para a vida humana nos tempos históricos. (GATTI, 2010, p.117).

Tal contexto incide em uma formação, como já dito anteriormente, a partir da complexidade do humano, numa formação que compreenda as mutações do tempo 
histórico e social, buscando a clareza de sua formação e dos fins dela. Lembramos que essa formação requer uma prática contextualizada, atenta às especificidades da cultura, das histórias de vida e das expectativas do momento. Tal prática requer conhecimento amplo, para além do ato de ensinar e aprender, para além do conhecimento acumulado pela humanidade. Que sejam favoráveis a uma postura profissional aberta ao novo, capaz de criar e buscar alternativas para os desafios que emergirem.

Nessa perspectiva, formar professores implica em formar pessoas que se comprometam com atitudes de respeito e de tolerância à diversidade racial, sexual, religiosa, social, econômica, financeira, etc. (GARCIA, 1999, p.92). Nesse caminho compactuamos com Freire (1996, p.35) quando diz que educar assumi um risco de aceitação do novo e rejeição de qualquer forma de discriminação.

Diante dessa fala, não poderemos negar o sentido inclusivo da formação de educadores, dado o sentido inclusivo da educação disposto nos mecanismos legais do nosso Estado brasileiro como a Constituição Federal, a LDB, o Estatuto da Criança e Adolescente - ECA. Da mesma maneira não podemos negar a educação como um direito fundamental de todos que, por sua vez, assegura outros direitos. Essencialmente a educação em direitos humanos implica na construção de conhecimentos que nos levam ao gozo da cidadania.

Para isso é necessário o comprometimento do Estado em reconhecer os direitos humanos, em ampliar a oferta de formação de professores que atuarão com a pobreza, a vulnerabilidade e a desigualdade social. Como assinala ARROYO (2017), a formação de educadores deve se aprofundar nos conhecimentos e nas correlações de poder sócio-política do trabalho nos quais estão se forjando, a fim de entenderem toda a dinâmica de produção/exploração do trabalho/trabalhador.

Por parte das instituições formadoras é fundamental que se construa um currículo comprometido com a complexidade do mundo moderno, empenhado em formar para novos valores, sem práticas conservadoras. Atentas às transformações sociais, porém responsáveis na preservação da memória. Um povo sem memória, é um povo sem referência.

Essas instituições formadoras devem voltar seus programas para a sensibilidade da vulnerabilidade humana. De uma maneira, ou de outra, as pessoas 
estão cada vez mais vulneráveis. Seja às exigências do mundo moderno, seja pelas exigências dos processos complexos de formação da pessoa humana.

O contexto que vivemos tem exigido do ser humano habilidades muito mais complexas dada a rapidez dos meios de comunicação, do avanço da ciência, da tecnologia e da própria estrutura social neoliberal e capitalista. O contexto apela para uma formação aligeirada, de finais de semanas, de certificação e de cunho econômico determinado pelo mercado e seu célere movimento, onde o comprometimento com a ciência da educação, e suas múltiplas áreas de conhecimento, fica em segunda estância.

Salientamos aqui a ausência de uma formação atenta ao contexto, atenta à temáticas que se apresentam no cotidiano da educação e da escola como a pobreza dos nossos alunos, como problemas de aprendizagens, problemas de bulling, de uso de drogas, de sexualidade, entre tantos outros problemas oriundos da sociedade. O que temos são cursos de formação voltados para a manutenção do capital, da ordem social e das forças de poder.

Perceber tal fenômeno requer sensibilidade à dimensão humana envolvida num processo de formação de educadores em duas vias. A primeira, parte da construção do conhecimento específico e o envolvimento com a área da educação. A segunda via origina-se na própria ação educadora, na prática social da educação, na prática inclusiva. Essa sensibilidade se traduzirá em trazer para o centro da ação educativa o vulnerável, o pobre, a desigualdade social.

Assim estaremos buscando uma formação que desperte e que se cumpra como direito humano numa sociedade marcada historicamente por desigualdades, mesmo vivendo em contextos de rápidas transformações nos campos social, econômico e, por que não dizer, educacional.

Ao analisarmos sobre a formação de professores como uma política que deve ser comprometida com as minorias e com o avanço da sociedade, consideramos sua influência no contexto, na formação de valores, no conhecimento e cumprimento de direitos humanos. Como diz Nóvoa (2002) qualquer projeto de formação transporta uma utopia, transporta um desejo transformador, uma inovação, mas também uma intenção. Seja com os vulneráveis, seja com os detentores do poder econômico. 
Nesse bojo, a escola e suas instituições formadoras de professores carregam intencionalidades que, vestidas de modernidade, de novos conhecimentos e de tecnologia, acabam reproduzindo a sociedade vigente $e$ as suas formas segregadoras. É preciso estarmos atentos aos currículos, àquilo que estamos ensinando, a quem estamos servindo e qual o jogo de poder circunscrito ao nosso entorno.

É necessário darmos lugar de privilégio à formação e suas instituições formadoras. Estas devem ressuscitar, tornarem-se vivas a ponto de envolver-se na busca pela efetivação de políticas públicas para a educação das minorias, pela consolidação de programas de formação continuada de professores, pelo envolvimento com as escolas periféricas, pelo conhecimento legal, pelo cumprimento dos direitos humanos. É necessário privilegiar a educação dos educadores, também, como ação transformadora e inclusiva. É fundamental que tenhamos aumento no investimento em pesquisas no campo educacional.

Para encerrar essas reflexões precisamos lembrar Paulo Freire (1996) quando diz: não há docência sem discência, mas sem uma boa docência não haverá uma educação de qualidade. É necessário pensarmos em nossas crianças, nossos jovens e adultos que estão em processo de escolarização. É necessário propormos uma educação voltada para o processo de humanização, para a garantia dos direitos humanos, para a cidadania.

Pela formação de professoras e professores, por um currículo crítico, social e humano e pela garantia dos direitos humanos e, acima de tudo pela garantia do direito à educação, acesso e permanência à escola fiquemos vigilantes à quaisquer ameaças à escola democrática, direito de todos e dever do Estado (BRASIL. Constituição Federal. 1988).

Em suma, o professor em formação precisa de ações educativas fundamentadas para a transformação da qualidade no caminho de uma prática voltada aos direitos humanos. Nesse bojo concordamos com Pimenta (1995, p. 61), quando diz que:

A essência da atividade (prática) do professor é o ensino aprendizagem. Ou seja, é o conhecimento técnico prático de como garantir que a aprendizagem se realize em consequência da atividade de ensinar. Envolve, portanto, o conhecimento do objetivo, o estabelecimento de finalidades e a intervenção no objeto para que a realidade seja transformada enquanto realidade social. (PIMENTA. 1995. p. 61). 
Esperamos com as ponderações estabelecidas ao longo desta escrita, termos deixado muito mais questionamentos, do que soluções, muito mais reflexões, do que proposições. Que sejam desafios para a nossa prática intelectual, de formação e atuação profissional na construção de uma educação comprometida com os direitos humanos, com o homem, o seu processo de humanização, e com a sociedade que acreditamos poder ser melhor, mais justa e mais digna. Assim meu ensejo é que possamos amadurecer esse olhar, sem esquecer o campo das pesquisas educacionais, não tratada nesta oportunidade, mas que suscita a sustentação do nosso campo de estudos: A Educação.

\section{ALGUMAS CONSIDERAÇÕES}

Ao iniciarmos este artigo objetivamos tecer reflexões sobre a relação da com educação com os direitos Humanos e a formação de professores na perspectiva das relações de poder que se constroem a partir dessas três categorias. Para isso iniciamos a nossa fala a partir de três extensões, onde na primeira, trouxemos 0 Estado à responsabilidade provedora de direitos e, correlato a isso a importância da participação social na vigilância da concretização desses direitos. A segunda, falamos dos mecanismos que o Estado se apropria para forjar esses direitos, por excelência no âmbito educacional, trazendo as reformas curriculares em consonância às políticas dominantes e, a terceira dimensão, originada por esse contexto, que trata da formação dos professores sua relação com a pobreza, com as desigualdades sociais e direitos humanos.

Podemos considerar que as reflexões e proposições se fundamentaram no campo da ciência educação, originando na Pedagogia, campo de nossa atuação profissional. Também trouxemos conhecimentos do referencial sócio histórico, das políticas educacionais e políticas curriculares como elementos que se permitiram dialogar na elucidação do nosso propósito e da formação e atuação de professores para os direitos humanos.

Consideramos neste artigo fundamental o papel do Estado como protagonista de direitos humanos, com ênfase ao direito educação mediante a consolidação de políticas públicas de Estado comprometida para a educação básica, a formação de educadores e de alcance social visando a minimização das desigualdades sociais. 
Um do aspecto relevante foi tecer sobre a importância das políticas curriculares para a educação e a formação de educadores comprometidos com a vulnerabilidade e a desigualdade social e, consequentemente com a inclusão social.

Ainda sobre as reflexões curriculares, um ponto significante foi quando trouxemos o currículo como princípio político carregado de intensões de quem as organiza, desde o seu processo de criação, condução e execução.

Diante das reflexões e proposições desenvolvidas sobre a formação de professores destacamos a importância da mesma está voltada aos direitos humanos, assim como relevamos o caráter de investimento político nas instituições formadoras em estarem voltadas aos direitos humanos.

Daí, sendo um tema atual e de grande importância social, os direitos humanos em educação pressupõe a sua compreensão, mas também o seu desenvolvimento nos diferentes níveis e modalidades de ensino, além de sua abrangência na comunidade escolar.

Para finalizar enfatizamos que as reflexões e proposições estabelecidas ao longo deste artigo possam ter possibilitado a identificação da educação, enquanto um direito humano e a sua íntima relação com o currículo e a formação de professores, assinaladas por sua política de formação vigente, além de ter contribuído para a construção de novas críticas e caminhos no campo relacional da educação, direitos humanos e formação de professores. 


\section{REFERÊNCIAS}

ARENDT, Hannah. Origens do totalitarismo. Tradução: Roberto Raposo. São Paulo: Companhia das Letras. 2012.

ARROYO, Miguel G. Passageiros da noite - do trabalho para a EJA: itinerários pelo direito a uma vida justa. Petrópolis, RJ: Vozes, 2017.

BALL, Stephen. Sociologia das políticas educacionais e pesquisa crítico social: uma revisão pessoal das políticas educacionais e da pesquisa em política educacional. In: BALL, Stephen \& MAINARDES, Jefferson (orgs). Políticas educacionais: questões e dilemas. São Paulo: Vozes. 2011

BRASIL. Constituição da República Federativa do Brasil. Brasília, DF: Senado Federal: Centro Gráfico, 1988.

BRASIL. Lei no 9.394. Estabelece as Diretrizes e Bases da Educação Nacional. Brasília, DF: Presidência da República Brasília. Centro Gráfico.1996.

BRASIL. Estatuto da Criança e do Adolescente, Câmera dos Deputados, Lei $n$. 8.069, de 13 de julho de 1990. DOU de 16/07/1990 - ECA. Brasília, DF.1990.

BRASIL. Instituto Nacional de Estudos e Pesquisas Educacionais Anísio Teixeira. Relatório do 10 ciclo de monitoramento das metas do PNE: biênio 2014- 2016. Brasília, DF: INEP, 2016.

CALDART, R. Pedagogia do Movimento Sem Terra: escola é mais do que escola. Rio de Janeiro: Vozes. 2000.

FREIRE, Paulo. Pedagogia da autonomia: saberes necessários à prática da autonomia. São Paulo: Paz e terra, 1996.

FREIRE, Paulo. Pedagogia do Oprimido. 17.ed. Rio de Janeiro: Paz e Terra. 1987.

GARCIA, Carlos Marcelo. Formação de professores para uma mudança educativa. Porto: Porto Editora, 1999.

GATTI, Bernardete Angelina. Formação de professores no Brasil: características e problemas. Educação \& Sociedade. v.3, n. 113, out/dez. São Paulo: Campinas, 2010.

HELENE, Otaviano. Um Diagnóstico da Educação Brasileira e de Seu Financiamento. Campinas: Autores Associados, 2013.

COLLET, J.\& TORT, A.(Coord.). La gobernanta escolar democrática. Morata: Madrid, 2016.

MARX, K. Ad Feuerbach. In: MARX, K, ENGELS, F. A ideologia alemã: crítica da mais recente filosofia alemã Feuerbach, B. Bauer e Stirner, e do socialismo alemão em seus diferentes profetas, p. 1845-1846. São Paulo: Boitempo Editorial. 2007. 
NÓVOA. António. Formação de professores e trabalho pedagógico. Lisboa: Porto Editora, 2002.

PIMENTA, S. G. O estágio na formação de professores: unidade teoria e prática? 2.ed. São Paulo: Cortez, 1995.

SANTOS, Boaventura. Se Deus fosse um ativista dos direitos humanos. São Paulo: Cortez Editora, 2013.

SAVIANI, Dermeval. Formação de professores: aspectos e teóricos do problema no contexto brasileiro. In: Revista Brasileira de Educação, v.14, n.40, jan/abr, 2009.

SUBIRATS, Joan (director); et al. Pobreza y exclusión social Un análisis de la realidad española y europea. Colección Estudios Sociales n.16. La Fundación "la Caixa”. España: Barcelona, 2004. Disponível em:

(https://www.researchgate.net/profile/Clara Riba/publication/301824451 Pobreza y exclusion social Un analisis de la realidad espanola y europea/links/5729ec3c 08ae057b0a076e20.pdf). Acesso em: 28/10/2020. 